\title{
Use of a Librarian/Consultant Team To Study Library Operations
}

A team approach to analysis of library operations is suggested. A specific example of staffing library information desks illustrates the complementary characteristics and advantages of using a librarian/consultant team. The example shows how lines of thought are developed by the team and the important aspects of cooperation between team members.

\section{INTRODUCTION}

$\mathrm{T}$ HE IDEA OF APPLYING SYSTEMS-ANALYSIS TECHNIQUES to study library operations is becoming quite popular. ${ }^{1}$ As complexity of the system increases, it certainly seems that logical analysis is necessary if the efficiency of a library system is to be maintained. However, several difficulties arise.

The most obvious problem is that librarians usually have, at most, only a cursory knowledge of the analytical tools available. The solution might be for the library to employ a full-time analyst on its staff. ${ }^{2}$ However, budgets and needs may limit this solution.

Librarians might be trained to use various "canned" models of library operations. If such quasi-analysts, however, do not understand the theoretical base of such models, they will have difficulty modifying the models for a particular library system, as well as keeping up with developments in mathematical modeling.

Mr. Rouse is research associate, Department of Mechanical Engineering, Massachusetts Institute of Technology, Cambridge, Massachusetts; Ms. Rouse is senior library assistant, Science Library, Massachusetts Institute of Technology.
The most reasonable solution for moderate-size libraries is the use of consultants. However, a system analyst after a little study, might argue that he could understand any system sufficiently to model its operation. Such a superficial attitude might have impractical results for the library system.

This paper discusses the use of a librarian/consultant team to model and study library operations. Without hiring a full-time analyst, this approach offers the advantage of applying systems techniques based on the assumptions and constraints explained by the librarian who has responsibility in the every day library system. The librarian has insights which the analyst cannot acquire in the few days normally available for observation. For example, the librarian is aware of the political constraints within the system which, as Churchman has pointed out, can be significant. ${ }^{3} \mathrm{Be}$ sides the importance of the librarian scrutinizing the analyst's assumptions and methods, the participation of the library staff is imperative to implement the results of any study. ${ }^{4}$

The most important aspect of using a librarian/consultant team is the combination of viewpoints. As the librarian discusses how the particular library system operates, the analyst mentally for- 
mulates the modeling approaches that seem applicable. The analyst then discusses the assumptions necessary for particular models with the librarian. During such discussion, the individuals (who each have a different set of professional jargon) are forced to articulate the exact meaning and limitations resulting from assumptions.

\section{An Example}

This example covers staffing of the information desks at MIT's Humanities Library. ${ }^{\circ}$ The study was self-initiated and often uses heuristic rather than actual situations. Initially, the librarian and consultant talked about their respective roles in the study. ${ }^{\circ}$ In this way, the librarian realized how much the consultant had to rely on the librarian's intuitive knowledge of the system's operation, particularly when large amounts of data could not be gathered. The team also discussed the credibility of a model's underlying assumptions.

The purpose of information desks is to answer inquiries either by phone or in person regarding general locations and union catalog information. There are two information desks in the library facing the entrance, each providing equal access for inquirers. Two identical telephone extensions are serviced by each desk.

The schedule for manning the desks at the time of this study (Nov. 5-15, 1971) was roughly one person (for both desks) during the mornings and weekends, and two people in the afternoons. The goal of this study was to determine if a schedule of staffing could be de-

- The authors gratefully acknowledge the cooperation of Humanities Librarian F. B. B. Sumner and the help in collecting data of $\mathrm{Li}$ brary Assistant S. Stillman.

$\because$ In actuality, the consultant may not be dealing with the librarian, but with the individual(s) most involved with the particular system or subsystem being analyzed. For convenience, the term librarian is used in a generic rather than a professional sense. vised to provide acceptable service at lower costs.

The librarian was able to point out areas of possible cost savings. Each information librarian has other primary responsibilities that cannot be performed while on desk duty. Because information-desk duty can interfere with an individual's other responsibilities, if each person could spend less time at the desks, then more time could be devoted to the primary areas of responsibility. Thus, without reducing staff size, this study proposed to increase output in other areas of library operation.

A queuing model of the information desks system seemed natural and was the first approach pursued. The analyst asked if it was reasonable to assume that service times for the two populations (i.e., phone and in-person inquiries) could be aggregated into a single service time distribution. The librarian felt that phone inquiries, on the average, took considerably longer time to complete than in-person inquiries. Thus, data was gathered by distinguishing phone from in-person inquiries. Data included the time between inquiry arrivals and the time it took to complete the service.

It was soon found that few inquiries were made in the morning and on weekends. Thus, this data was not analyzed because it was clear that an additional person was not needed at the desks during those times. Also, the staffing could not be further reduced, since that would leave the unacceptable situation of no service at all. Hence, only the data gathered during the afternoon was considered.

Figures 1 and 2 show histograms of service times for phone inquiries, inperson inquiries, and interarrival times for each. To determine average inquiry rates ( $\lambda_{1}$ for phone inquiries and $\lambda_{2}$ for in-person inquiries) and average service rates ( $\mu_{1}$ for service of phone inquiries and $\mu_{2}$ for service of in-per- 


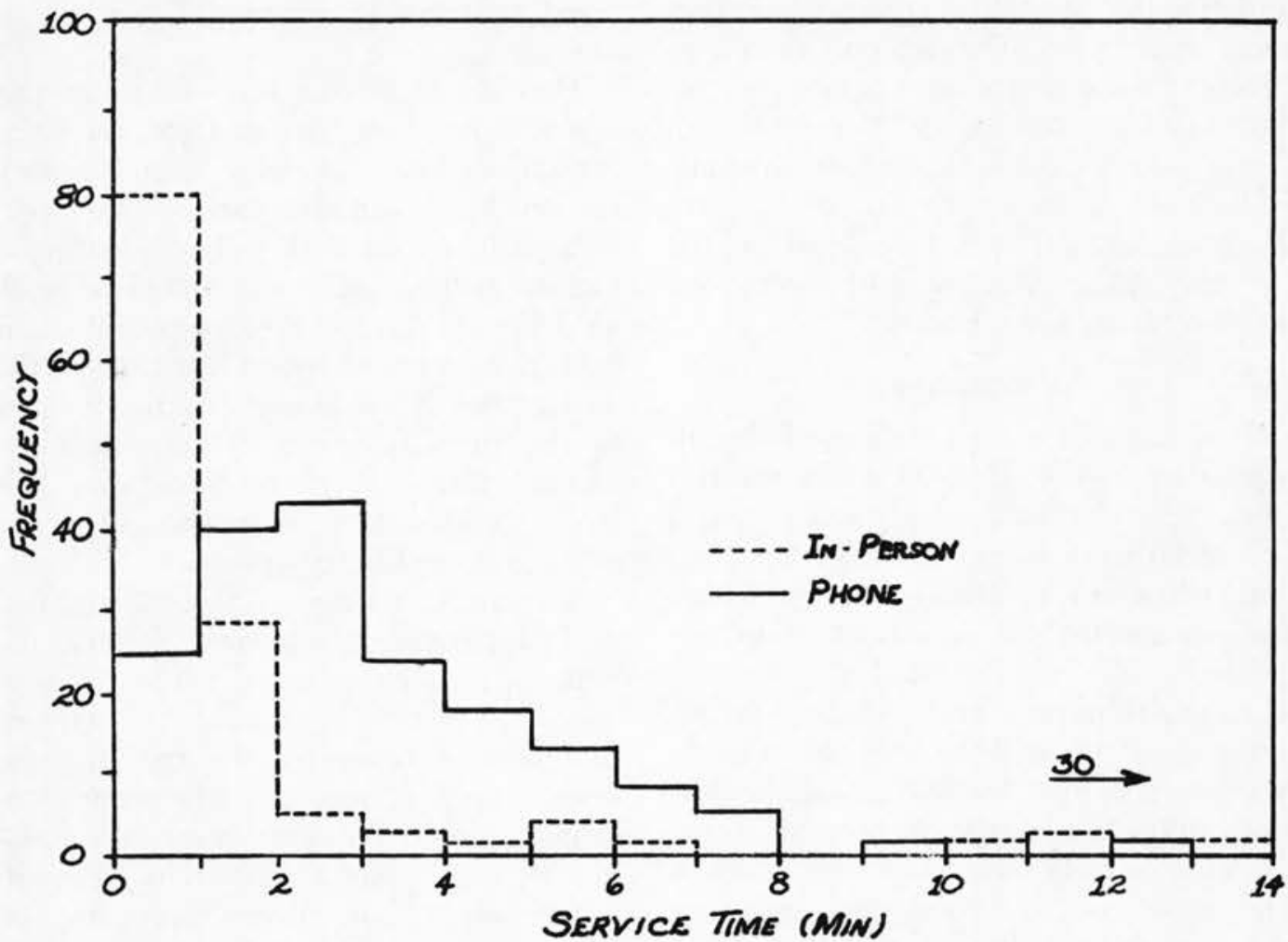

Histogram of Service Times

Fig. 1

son inquiries), the data was replotted in Figure 3. Plotting the data and analyzing as discussed by Morse, the following were determined:

$$
\begin{aligned}
& \lambda_{1}=0.115 \text { inquiries } / \text { minute } \\
& \lambda_{2}=0.091 \text { inquiries } / \text { minute } \\
& \mu_{1}=0.331 \text { services } / \text { minute } \\
& \mu_{2}=0.642 \text { services } / \text { minute. }{ }^{5}
\end{aligned}
$$

The $\mu$ 's are reasonably accurate and the difference between $\mu_{1}$ and $\mu_{2}$ is consistent with the librarian's initial intuition. The $\lambda$ 's are definitely low. This is due to the inability to measure how often a phone inquirer found the two phones busy or how often an in-person inquirer was discouraged by seeing other inquirers waiting at the information desks for service. The team discussed this point thoroughly. The librarian could easily understand how the data originated: she collected it. However, for results to re- main credible to the librarian, the analyst had to explain why he was going to "adjust" the data. The data is adjusted in either of the following ways:

1. A measurement must be made of how often both phones are busy, and how often both desks have sufficient inperson inquirers to discourage further inquirers.

2. The librarian must estimate these measurements. The situation dictated the second choice. Queue lengths must be assumed (infinity could be a choice). The librarian made the following decisions:

a. In-person queue length of zero: no more than two inquirers will be at the information desks at one time. ${ }^{\circ \circ}$ zero.

$\cdots$ Phone queue length necessarily equals 


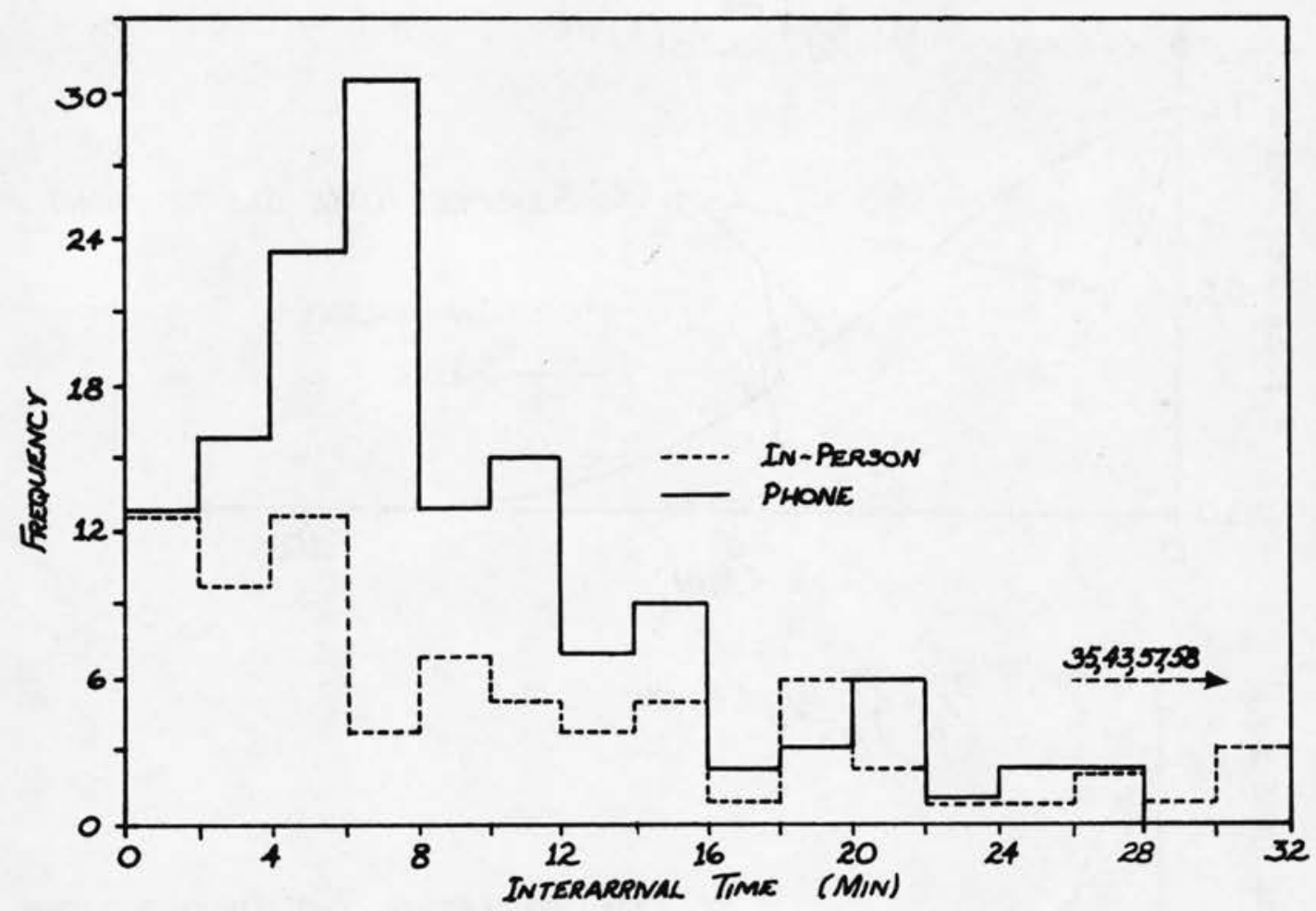

Histogram of Interarrival Times

Fig. 2

$b$. Two phones are in use at the same time approximately three times per hour.

c. Two in-person inquirers are at the desks at the same time approximately two times per hour.

The librarian and consultant agreed that if decisions $b$ and $c$ were to be biased, it should be in the direction of overestimating the load on the system. Thus, results using such estimates would be conservative with respect to decreasing staffing at the desks.

With the above decisions and using discussion presented in Morse, a relationship for estimating the actual arrival rate $\lambda_{T}$ was derived.

$$
\lambda_{\mathrm{T}}=\frac{\lambda}{\left(\frac{1-\text { frequency of full queue }}{\mu}\right)}
$$

Using (1) the data becomes (subscript $\mathrm{T}$ dropped for convenience):

$$
\begin{aligned}
& \lambda_{1}=0.136 \\
& \lambda_{2}=0.096 \\
& \mu_{1}=0.331 \\
& \mu_{2}=0.641
\end{aligned}
$$

With these numerics, the system utilization $\rho$ and average idle period $1 / \lambda$ can be estimated. System utilization is the percentage of time the system is busy and is given by

$$
\rho=\frac{\lambda}{2 \mu} \text { (for two servers). }
$$

$\lambda$ is the total inquiry rate given by

$$
\lambda=\lambda_{1}+\lambda_{2}=0.232,
$$

and $\mu$ is the average service rate given by

$$
\begin{gathered}
\mu=\left(\frac{\lambda_{1}}{\lambda_{1}+\lambda_{2}}\right) \mu+\left(\frac{\lambda_{2}}{\lambda_{1}+\lambda_{2}}\right) \mu_{2} \\
=0.459 .
\end{gathered}
$$

Combining (2) through (4), $\rho$ equals 0.253 , which means that 75 percent of the time neither desk is servicing any 

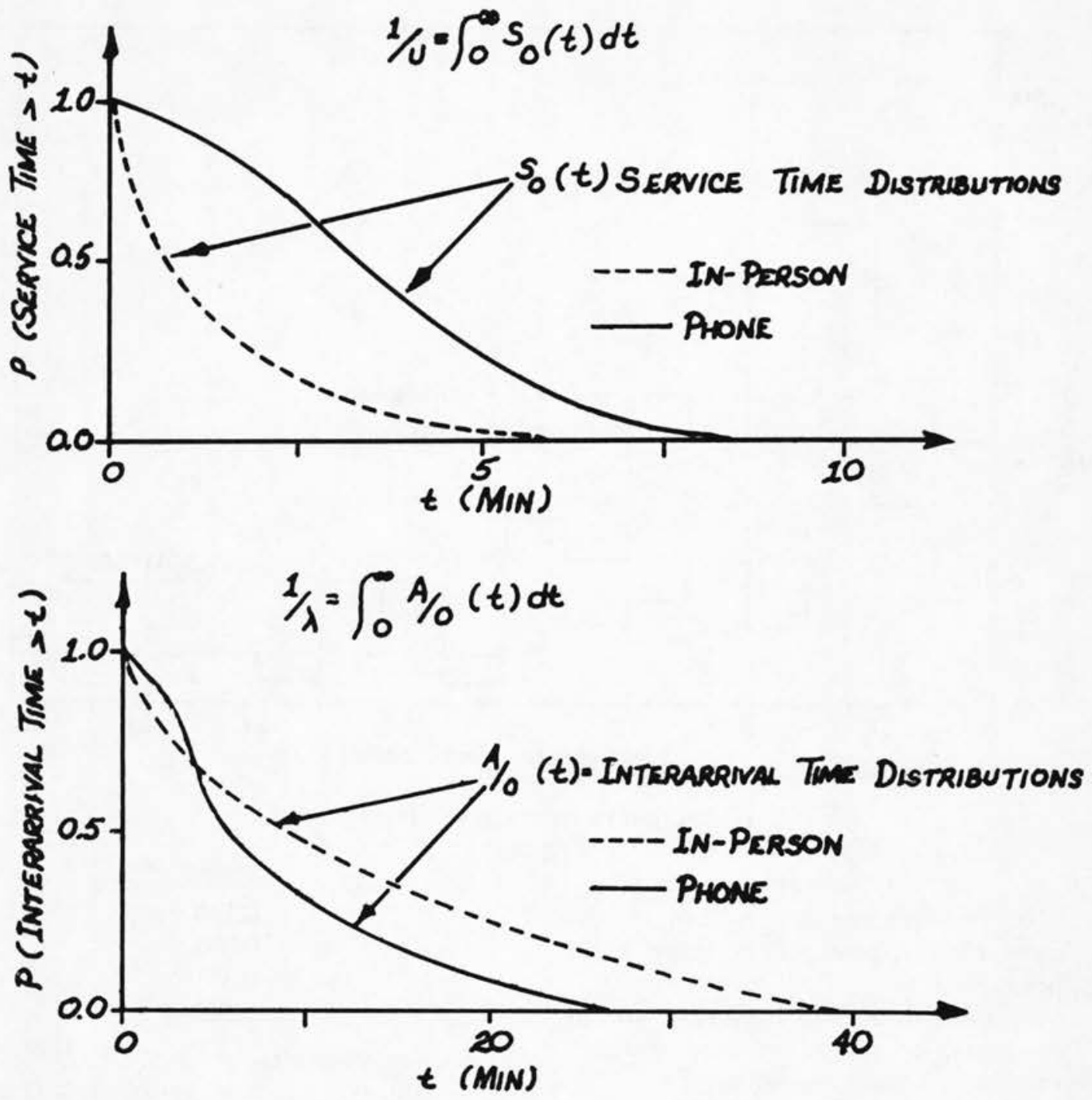

Service and Interarrival Time Distributions

Fig. 3

type of inquirer. The average period that this idle situation exists is $4.3 \mathrm{~min}$ utes.

For the purpose of comparison, if there were only one librarian on duty during this period, then

$$
\rho=\frac{\lambda}{\mu}=0.506 \text {. }
$$

Morse suggests that $\rho<0.667$ will yield library service that will not cause excessive delays. Thus, one librarian would be sufficient during the period analyzed. The single librarian will be much busier than with two librarians on duty. How- ever, if the total staff is maintained at its current size, each librarian would spend over 30 percent less time at the information desks.

These results pointed toward further applications of systems analysis data. In addition to data collection, the librarian was interested in other models that might yield more information about the system. A Markov model was discussed. ${ }^{6}$

The following Markov model was proposed for further study of the information desks system. The possible states of the system are listed in this Markov model: 


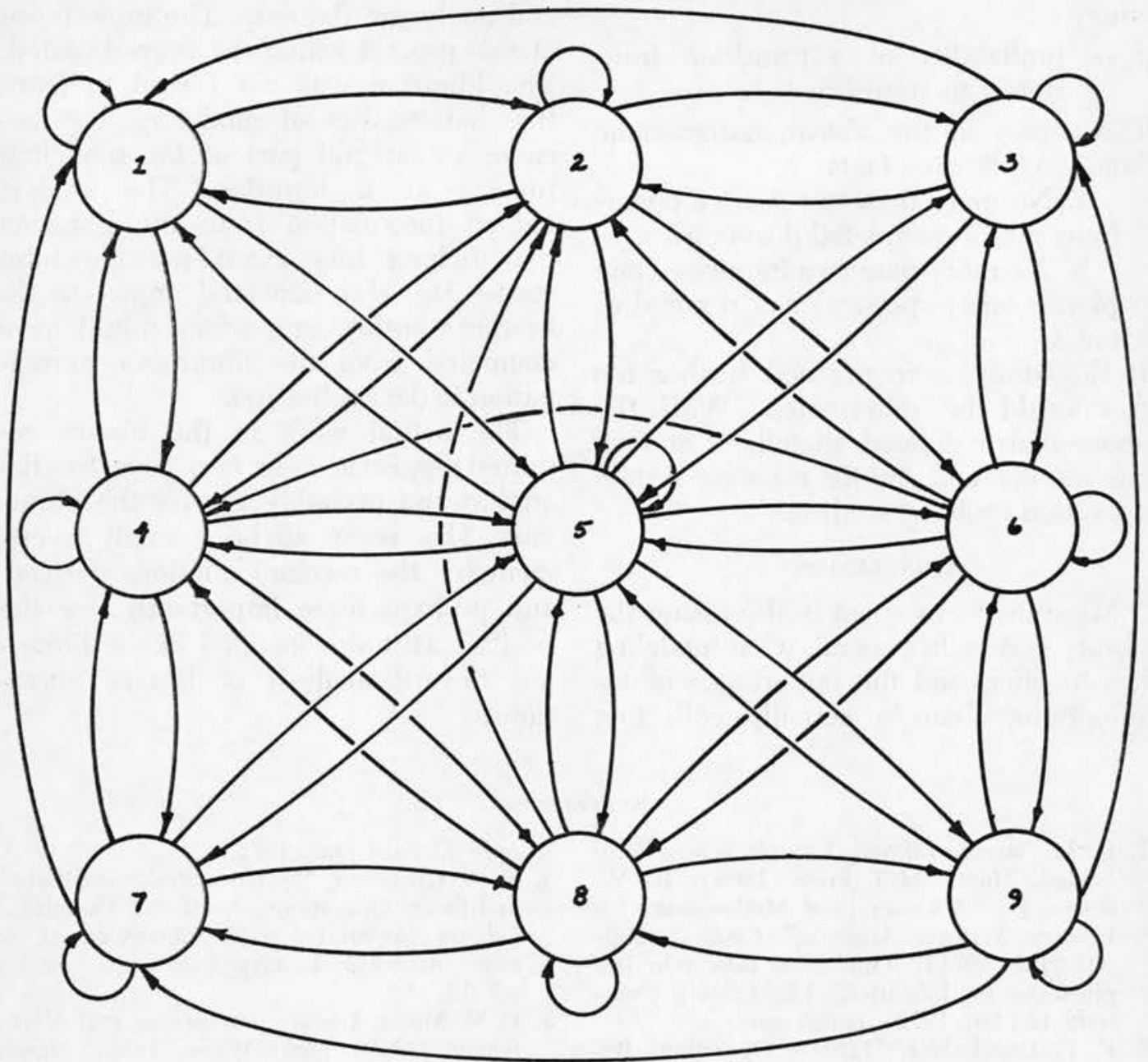

A Markov Model of the Information Desks System Fig. 4

\begin{tabular}{ccc}
\hline State & Phones in use & In-Person inquirers \\
\hline 1 & 0 & 0 \\
2 & 0 & 1 \\
3 & 0 & 2 \\
4 & 1 & 0 \\
5 & 1 & 1 \\
6 & 1 & 2 \\
7 & 2 & 0 \\
8 & 2 & 1 \\
9 & 2 & 2 \\
\hline
\end{tabular}

The model requires the probabilities of a transition from one state to another in a time interval $\Delta t$. As exponential service times and interarrival times have been implicitly assumed, it is known that at most one phone call and one inperson inquiry can occur in $\Delta t$. Using this property, the Markov model is illustrated in Figure 4 . The lines with arrows represent transitions between states. Note that some transitions are not possible. The probabilities of a transition can be more conveniently represented with the following transition matrix.

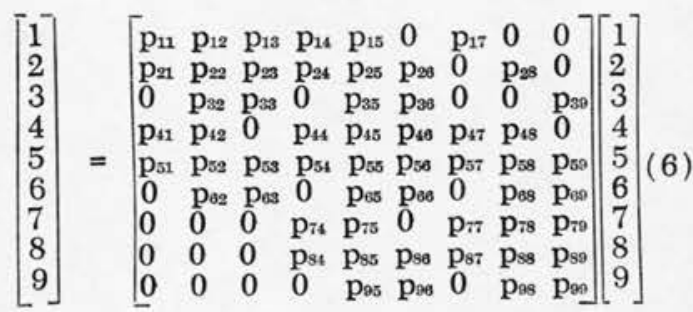


where

$\mathrm{p}_{\mathrm{ij}}=$ probability of a transition from state $\mathrm{i}$ to state $\mathrm{j}$ in time $\Delta \mathrm{t}$.

The zeroes in the above matrix came from the following facts:

a. No more than two service operations can be completed during $\Delta t$.

b. No more than two inquiries (one phone, one in-person) can occur during $\Delta t$.

If this study were pursued further the $p_{i j}$ 's could be determined. With the above matrix defined, the effects of various inquiry and service rates on system operation could be studied.

\section{Conclusion}

More time was spent in discussing the library system in general, what modeling has to offer, and the importance of assumptions, than in actually collecting and analyzing the data. The importance of this process cannot be overestimated. The librarian was not forced to learn the mathematics of modeling, but became an integral part of the modeling process as a librarian. The analyst gained information from the librarian that helped him avoid possible false starts. He also benefited from the librarian's enthusiasm, which might have emanated from the librarian's participation in data collection.

The actual work in the library required approximately two days for the analyst and probably less for the librarians. This seems to be a small investment for the recommendations derived, and perhaps more importantly, for the positive attitudes instilled in the librarians toward analysis of library operations.

\section{ReFERENCES}

1. P. M. Morse, Library Effectiveness (Cambridge, Mass.: MIT Press, 1968); R. W. Burns, Jr., "A Generalized Methodology for Library Systems Analysis," CRL 32:295303 (July 1971); “Operations Research: Implications for Libraries," The Library Quarterly 42 (Jan. 1972), entire issue.

2. F. F. Leimkuhler, "Library Operations Research: A Process of Discovery and Justification," The Library Quarterly 42:84-96 (Jan. 1972).

3. C. W. Churchman, "Operations Research Prospects for Libraries," The Library Quar- terly 42:6-14 (Jan. 1972).

4. E. A. Chapman, "Systems Study as Related to Library Operations: Need and Planning," Library Automation, S. R. Salmon, ed. (Chicago: American Library Association, 1969), p.7-12.

5. P. M. Morse, Queues, Inventories and Maintenance (New York: Wiley, 1958), chapt. 2.

6. See A. W. Drake, Fundamentals of Applied Probability (New York: McGraw-Hill, 1967), chapt. 5. 